\title{
POTENSI DAN TINGKAT PEMANFAATAN SUMBERDAYA IKAN DEMERSAL DI PERAIRAN PULAU AMBON PROVINSI MALUKU
}

\author{
POTENTIAL AND UTILIZATION OF WATER RESOURCES IN THE ISLAND \\ DEMERSAL AMBON PROVINCE MALUKU
}

\author{
Donald Noija ${ }^{1}$, Sulaeman Martasuganda ${ }^{2}$, Bambang Murdiyanto², Am Azbas Taurusman ${ }^{2}$ \\ ${ }^{1}$ Program Studi Teknologi Perikanan Laut, Sekolah Pascasarjana \\ ${ }^{2}$ Departemen Pemanfaatan Sumberdaya Perikanan \\ Fakultas Perikanan dan Ilmu Kelautan, Institut Pertanian Bogor \\ Korespondensi :ongki_noija@yahoo.co.id
}

\begin{abstract}
One of the fishery resources that have high economic value are demersal fisheries resources in deep sea waters. The results ofthis study found 22 demersal fish species with high economic value captured by fishermen. The results ofthe study found as many as 22 species, five fish stretcher 5 that can be foundin nearly all areas and fishing season. Five types of fish are: lencam (Lethrinus sp.), kurisi (Etelis spp), kerapu (Ephinephelus sp), red snapper (Lutjanus spp), bubara fish (Caranx sp). The types of fish catches were found spread around the waters of Ambon Island. The potential at Maxsimum sustainable Yield (MSY) of fish grouper (Epinephelus spp) 572.02 with 15.75 tonnes optimum effort trip. The average production of 178.919 tonnes currently. Thus the average utilization rate of groupers currently $31.27 \%$ or $68.72 \%$ untapped. If it is based on the MSY allowable catch for the fish species is 457.60 tons / year. MSY red snapper (Lutjanus spp) 146.83 wih 2.631 tonnes optimum effort trip. Average production is currently 67.704 tons. Thus the average utilization rate of the red snapper fish is currently $47.47 \%$, or in other words the potential for red snapper untapped $52.52 \%$. If it is based on the MSY allowable catch for the fish species is 117464 tons / year. MSY bubara fish (Caranx sp) 270.60 tonnes with optimum effort 3630 trip with an average yield of 72.96 tons.
\end{abstract}

Keywords: Catch per Unit Effort, fish resources, Maximum Sustainable Yield, utilization

\begin{abstract}
ABSTRAK
Salah satu sumberdaya perikanan yang memiliki nilai ekonomis tinggi adalah sumberdaya perikanan demersal di perairan dalam. Hasil penelitian ini mendapati 22 jenis ikan demersal dengan nilai ekonomis tinggi yang ditangkap oleh nelayan. Hasil penelitian ditemukan sebanyak 22 jenis ikan dari berbagai jenis, ada 5 jenis yang mendominasi hasil tangkapan dari sisi jumlah maupun frekuensi kehadiran atau yang dapat ditemukan hampir diseluruh daerah dan musim penangkapan. Lima jenis ikan tersebut adalah lencam (Lethrinus sp), kurisi (Etelis spp), kerapu (Ephinephelus sp), kakap merah (Lutjanus spp), Ikan bubara (Caranx sp). Jenis-jenis ikan hasil tangkapan tersebut ditemukan menyebar di sekitar perairan Pulau Ambon. Potensi pada tingkat lestari (MSY) ikan kerapu (Epinephelus spp) sebanyak 572.02 ton dengan upaya optimum 15.75 trip. Produksi rata-rata saat ini sebesar 178.919 ton. Tingkat pemanfaatan rata-rata ikan kerapu saat ini sebesar $31.27 \%$ atau yang belum dapat dimanfaatkan sebesar $68.72 \%$. Jumlah tangkapan yang didasarkan pada nilai MSY diperbolehkan untuk jenis ikan tersebut adalah 457.60 ton/tahun. MSY ikan kakap merah (Lutjanus spp) 146.83 ton dengan upaya optimum 2.631 trip. Produksi rata-rata saat ini 67.704 ton. Tingkat pemanfaatan rata-rata ikan kakap merah saat ini sebesar $47.47 \%$ atau dengan kata lain potensi ikan kakap merah yang belum dimanfaatkan sebesar 52.52\%. Peluang pemanfaatan pada nilai MSY maka jumlah tangkapan yang diperbolehkan untuk jenis ikan tersebut adalah 117.464 ton/tahun. MSY ikan bobara (Caranx sp) 270.60 ton dengan upaya optimum 3630 trip dengan produksi rata-rata 72.96 ton.
\end{abstract}

Kata kunci: Catch per Unit Effort, Maximum Sustainable Yield, pemanfaatan, sumberdaya ikan 


\section{PENDAHULUAN}

Sumberdaya perikanan termasuk sumberdaya alam yang dapat diperbaharui (renewable resources) akan tetapi upaya pemanfaatan tanpa mempertimbangkan kemampuan untuk pulih kembali telah menyebabkan sumberdaya perikanan di beberapa wilayah perairan menjadi hancur, dan mengalami kepunahan. Naamin dan Harjamulia (1990) mengemukakan bahwa sumber daya perikanan yang tersedia melimpah dan mempunyai kemampuan pulih kembali namun tanpa adanya usaha pengawasan terhadap penangkapan yang berlangsung terus-menerus dapat memperbesar kemungkinan terjadinya over fishing di beberapa perairan maupun daerah penangkapan. Guna menjamin keles-tarian sumber daya maka pemanfaatannya tidak boleh melebihi potensinya (FAO 1995).

Permintaan terhadap daging ikan oleh masyarakat di Pulau Ambon termasuk jenis ikan demersal cenderung mengalami peningkatan selain karena permintaan pengusaha lokal untuk tujuan ekspor, juga permintaan pasar lokal maupun sejumlah restoran seafood di Kota Ambon dan sekitarnya. Kondisi ini mengakibatkan upaya penangkapan mulai mengarah ke upaya pemanfaatan untuk tujuan komersil. Salah satu penyebab menurunnya sumberdaya perikanan adalah meningkatnya tekanan penangkapan akibat penambahan jumlah armada dan alat penangkapan ikan. Selain itu metode penangkapan sering tidak mempertimbangkan dampaknya terhadap lingkungan seperti penggunaan bom dan sianida yang cukup marak akhir-akhir ini. Beberapa hasil penelitian menyatakan bahwa penyebab utama gangguan ekologi sumberdaya dan ekosistem adalah manusia (Dahdouh-Guebas et al. 2005b \& LopezHoffman et al. 2006).

Sumberdaya ikan demersal di perairan dangkal sering menjadi sasaran eksploitasi karena nilai jual yang relatif tinggi dan juga kemudahan menjangkau daerah penangkapan. Akan tetapi belum diketahui berapa besar potensi dan tingkat pemanfaatannya. Saat ini nelayan lokal yang sudah sejak dulu memanfaatkan sumberdaya pada area dimaksud mulai meraskan gejala menurunnya hasil tangkapan. Upaya penangkapan ikan demersal di perairan lebih dalam (>20-100 $\mathrm{m})$ yang sejak dulu digeluti sebagian nelayan di Pulau Ambon penting dikaji untuk dikembangkan, sehingga menghindari tekanan di perairan dangkal (20 m), sebagaimana yang dikemukakan Badrudin \& Karyana (1992) bahwa nelayan biasanya mengoperasikan alat tangkap ikan demersal pada kedalaman $20 \mathrm{~m}$.

Perairan Pulau Ambon hingga kedalaman dimaksud dimana ekosistem terumbu karang dijumpai merupakan basis penangkapan ikan demersal oleh nelayan di Pulau Ambon. Berbagai jenis alat penangkapann yang digunakan ikan antara lain: jaring insang dasar (bottom gill net), mini trawl, rawai, bubu, pancing tangan, tombak dan panah. Pengoperasian jenis-jenis alat penangkapan ini jika terus menerus dilakukan tanpa memperhatikan dampak yang ditimbulkan terutama pada dasar perairan yang didominasi oleh terumbu karang maka cepat atau lambat akan menyebabkan kerusakan lingkungan dan sumberdaya hayati didalamnya bahkan kerugian manusia yang memanfaatkannya.

Berdasarkan hasil pengamatan ekosistem terumbu karang yang dijumpai di kedalaman $20 \mathrm{~m}$ di daerah penangkapan sekitar perairan Pulau Ambon dapat dikategorikan cukup baik, namun di beberapa lokasi dinyatakan dalam kondisi buruk akibat penangkapan tidak bertanggung jawab seperti penggunaan bom dan racun ikan. (Odum 1955 \& Connell 1978) menyatakan bahwa terumbu karang adalah salah satu ekosistem yang paling produktif dan beragam secara hayati di Bumi. Hampir sepertiga dari spesies ikan laut dunia ditemukan di terumbu karang (McAllister 1991) dan hasil tangkapan dari daerah terumbu karang menghasilkan sekitar 10\% sumberdaya ikan yang dikonsumsi oleh manusia (Smith 1978). Untuk itu pemanfaatan sumberdaya ikan demersal sebaiknya diarahkan ke perairan yang lebih dalam, agar mengindari kerusakan pada ekosistem terumbu karang perairan dangkal yang penting bagi keberlanjutan sumberdaya.

Sebagian besar studi terbaru ikan demersal pada perairan yang lebih dalam dititik beratkan pada penilaian sumberdaya (Moffit 2003). Serangkaian data perikanan sebelumnya dari hasil tangkapan dan usaha yang ada untuk kepentingan perkiraan MSY dapat diperoleh dengan menggunakan model surplus produksi antara lain model schaefer yang telah diterapkan pada perikanan laut dalam termasuk area slope dari ikan demersal yang dikenal sebagai perikanan multi-species di Hawaii. Akan tetapi dibutuhkan waktu yang cukup 
panjang untuk menyediakan data karena baru berkembangan perikanan demersal untuk pulau-pulau di Pasifik dan daerah lain disekitarnya (Ralston \& Polovina 1982).

Sumberdaya ikan demersal di perairan Pulau Ambon sudah dimanfaatkan sejak dulu, namun informasi tentang besar potensi dan tingkat pemanfaatan belum diketahui. Salah satu pendekatan untuk menjaga keseimbangan pemanfaatan sumberdaya adalah melalui pendekatan biologi yaitu menentukan besarnya upaya pada tingkat MSY yang merupakan cara sederhana untuk mengelola sumberdaya dengan mempertimbangkan bahwa eksploitasi berlebihan sumberdaya menyebabkan hilangnya produktivitas (Kar \& Chakraborty 2009). Adapun Tujuan penelitian ini adalah menentukan potensi di Maluku khususnya dipulau Ambon, dan menentukan tingkat pemanfaatan sumberdaya ikan demersal di perairan Pulau Ambon.

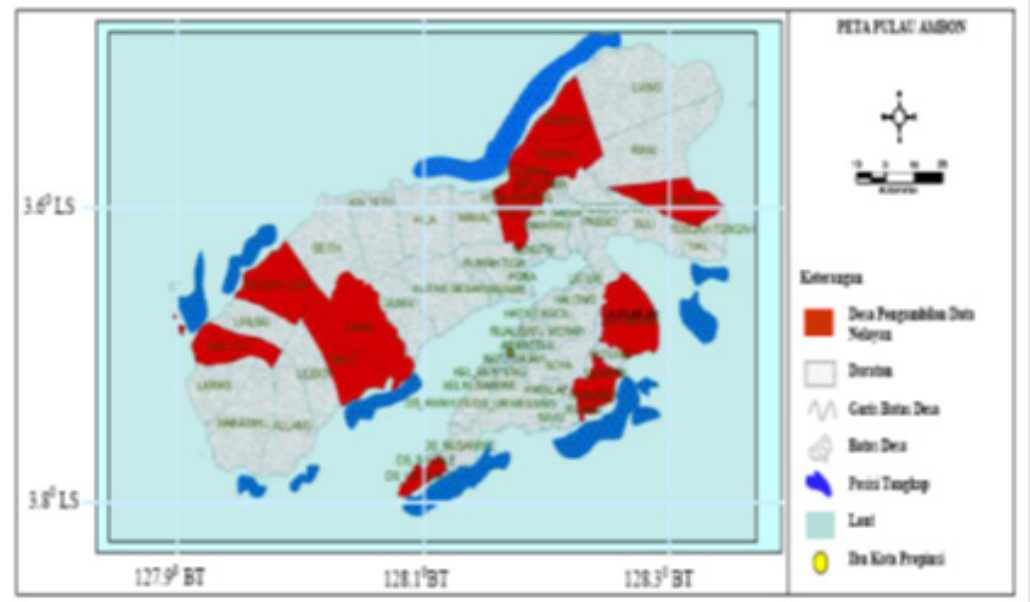

Gambar 1. Sebaran daerah penangkapan jenis-jenis ikan demersal di perairan Pulau Ambon

\section{METODE PENELITIAN}

Penelitian dilakukan di perairan Pulau Ambon sejak Januari-April 2014. Data meliputi data primer dan sekunder. Data primer diperoleh dengan cara pengamatan dan wawancara dengan menggunakan kuisioner untuk mendapatkan jenis dan ukuran ikan serta sebaran daerah penangkapan. Jenis ikan hasil tangkapan nelayan diukur dan selanjutnya diidentifikasi dengan menggunakan buku petunjuk identifikasi menurut Anderson \& Allen (2001) dan Allen et al. (2003), sedangkan data sekunder diperoleh dari Laporan Tahunan Dinas Perikanan dan Kelautan Kota Ambon periode 2005-2010. Data ini digunakan untuk kepentingan pendugaan potensi dan tingkat pemanfaatan sumberdaya ikan demersal di perairan Pulau Ambon. Pengumpulan data primer dilakukan secara langsung di lapangan dengan mengidentifikasi jenis dan ukuran bahan penyusun pancing ulur serta gambar peta yang digunakan untuk menentukan posisi lokasi pemancingan Gambar 1.

\section{Catch per Unit Effort (CPUE)}

CPUE dihitung untuk mengetahui kelimpahan dan tingkat pemanfaatan sumber daya perikanan di wilayah perairan tertentu. Perhitungan dilakukan setelah data produksi dan upaya (effort) ditabulasi menurut jenis alat tangkap. Upaya dalam penelitian ini adalah trip penangkapan. Perhitungan CPUE dilakukan dengan pendekatan sebagai berikut:

$$
\text { CPUE }_{t}=\frac{\text { Catch }_{t}}{\text { effort }_{t}}
$$

Keterangan:

$C P U E_{t}=$ hasil tangkapan per upaya penangkapan pada tahun ke-t

Catch $_{t}=$ hasil tangkapan pada tahun ke-t effort $_{\mathrm{t}}=$ upaya penangkapan pada tahun ke-t

\section{Standarisasi alat tangkap}

Alat tangkap yang umumnya digunakan untuk penangkapan jenis ikan demersal di Perairan Pulau Ambon adalah: 
rawai, pancing tangan, bubu dan gillnet tetap. Hal ini dikarenakan tiap alat memiliki kemampuan tangkap yang berbeda, maka standarisasi dilakukan untuk menghitung input upaya secara agregat. Jika standarisasi tidak dilakukan maka tidak mungkin dapat menjumlahkan total input agregat (total effort) dari perikanan yang dianalisis (Fauzi \& Anna 2005). Alat tangkap standar adalah yang memiliki produktivitas tertinggi dalam penangkapan suatu jenis ikan, atau mempunyai rata-rata CPUE terbesar dengan indeks kemampuan tangkap (fishing power index) satu. Standarisasi alat tangkap ke $\mathrm{n}$ pada periode waktu $t$ adalah:

$$
E_{s t d}=\varphi_{n t} E_{n t}
$$

Фxt diukur berdasarkan rasio CPUE dari alat tangkap terhadap alat tangkap standar pada periode waktu $t$.

$$
\varphi_{n t}=\frac{U n_{t}}{U_{s t d}}
$$

Keterangan:

$$
\begin{array}{ll}
E_{s t d} & =\text { Effort standar } \\
\Phi_{n t} & =\text { indeks kemampuan alat tangkap } \\
& \text { jenis ke } \mathrm{n} \text { pada waktu } \mathrm{t} \\
E_{n t} & =\text { Upaya nominal alat tangkap ke-n } \\
& \text { pada waktu } \mathrm{t} \\
U_{n t} & = \\
\quad & \text { CPUE alat tangkap ke-n pada } \\
U_{s t d} \quad & \text { waktu } \mathrm{t} \\
& \text { CPUE alat tangkap standar }
\end{array}
$$

Pendugaan potensi lestari dan tingkat pemanfaatan

Analisis Potensi pada tingkat lestari (MSY) dilakukan melalui 5 model/ pendekatan. Dari ke-5 model tersebut akan ditentukan salah satu model terbaik yang menggambarkan keadaan sebenarnya dari objek yang diteliti. Kelima pendekatan tersebut sebagai berikut:

Disequilibrium Schaefer

$$
\ln U_{(t+1)}-U_{(t-1)}=\mathrm{r}-\frac{r}{q K} U_{t}-q E_{t}
$$

Schaefer

$$
\begin{aligned}
Y & =a-b x . Y=c / f \\
x=f M S Y & =a / 2 b f_{\text {optimum }}=a^{2} / 4 b
\end{aligned}
$$

Walter-Hilborn

$$
\frac{U_{t+1}}{U_{t}}-1=r-\frac{r}{q K} \quad U_{t}-q E_{t}
$$

Schnute

$\ln \frac{U_{t+1}}{U_{t}}=r-\frac{r}{q K}\left(\frac{U_{t+1}+U_{t}}{2}\right)-q\left(\frac{E_{t}+E_{t+1}}{2}\right)$

Clark, Yoshimoto, dan Pooley (CYP)

$$
\begin{aligned}
& \ln U_{(t+1)} \frac{2 r}{2+r} \ln (q K)+\frac{2-r}{2+r} \ln \left(U_{t}\right)-\frac{q}{2+r} \\
& \left(E_{t}+E_{t+1}\right)
\end{aligned}
$$

Keterangan:

Ut = CPUE pada waktu $\mathrm{t}$

$U_{t+1} \quad=$ CPUE pada waktu $\mathrm{t}+1$

$E t \quad=$ Effort pada waktu $\mathrm{t}$

$E_{t+1} \quad=$ Effort pada waktu $\mathrm{t}+1$

$H_{t} \quad=$ Hasil tangkapan pada waktu $\mathrm{t}$

$K \quad$ = Daya dukung lingkungan

$r \quad=$ Konstanta pertumbuhan alami

$q \quad=$ Koefisien daya tangkap

Penggunaan model terbaik yang dengan melakukan pengukuran untuk menentukan goodness of fit suatu model penduga.

Penentuan/pengukuran dilakukan melalui:

1. Membandingkan nilai $\mathbf{r}^{2}$-nya

2. Kesesuaian tandanya

3. Penyimpangan yang terkecil

\section{HASIL DAN PEMBAHASAN}

\section{Jenis dan distribusi}

Perairan Pulau Ambon merupakan salah satu daerah penangkapan (fishing ground) potensial dari berbagai jenis sumberdaya perikanan. Mulai dari perairan pantai (in shore) hingga lepas pantai (off shore), di permukaan perairan (pelagic) hingga laut dalam (deep sea). Sumberdaya perikanan di wilayah tersebut sudah dimanfaatkan sejak dulu oleh nelayan setempat. Hasil pengamatan dan wawancara terhadap 109 responden diketahui jenis ikan demersal yang tertangkap oleh nelayan di wilayah ini sebanyak 22 jenis (Tabel 1).

Hasil penelitian ditemukan sebanyak 22 jenis ikan tersebut (Tabel 2), diperoleh 5 jenis ikan yang dominan tertangkap dari sisi jumlah maupun periode penangkapan yakni lencam (Lethrinus sp), kurisi (Etelis spp), kerapu (Ephinephelus sp), kakap merah (Lutjanus spp), ikan bobara (Caranx sp). Kelima jenis ikan ini selanjutnya digunakan untuk menganalisis besar potensi dan tingkat pemanfaatan sumberdaya ikan demersal di perairan Pulau Ambon. Data yang digunakan adalah data tahunan Dinas perikanan dan Kelautan Kota Ambon 
periode 2005-2010.

Jenis-jenis ikan tersebut di atas ditemukan menyebar di sekitar Perairan Pulau Ambon. Sebaran daerah penangkapan berdasarkan hasil survei dan wawancara dengan nelayan diperoleh 30 lokasi atau Daerah Penangkapan Ikan (DPI). Sebaran lokasi penangkapan berdasarkan wilayah perairan disajikan pada Gambar 1 .

Distribusi jenis-jenis ikan tersebut sangat dipengaruhi musim (Tabel 2). Kondisi ini teridentifikasi berdasarkan konsentrasi nelayan saat melakukan aktivitas penangkapan. Musim timur (Mei-September) konsentrasi nelayan penangkap berada di wilayah perairan Leihitu. Musim peralihan II sampai musim barat (September-Februari) aktivitas penangkapan ikan demersal berlangsung di wilayah perairan Teluk Ambon Luar dan perairan Nusaniwe. Pada musim barat (Desember-Februari) aktivitas penangkapan berlangsung di wilayah perairan Leitimur Selatan. Aktivitas penangkapan jenis-jenis ikan demersal dapat berlangsung sepanjang tahun di wilayah perairan Salahutu, dengan mayoritas nelayan beraal dari Negeri Tulehu. Masyarakat di negeri ini $\pm 90 \%$ adalah nelayan.

Wilayah perairan yang merupakan lokasi penangkapan jenis-jenis ikan tersebut berdasarkan informasi yang diperoleh dari hasil pemetaan sumberdaya ikan di Provinsi Maluku, Dinas Perikanan dan Kelautan Provinsi Maluku (2007) diketahui bahwa lokasi-lokasi tangkap tersebut memiliki substrat dasar pasir, berbatu dan terumbu karang yang sangat sesuai sebagai habitat dari jenis-jenis ikan demersal. Jenis-jenis ikan ini menyebar dari kedalaman 20 hingga $>100 \mathrm{~m}$.

\section{Potensi dan tingkat pemanfaatan}

Pemanfaatan sumberdaya ikan demersal oleh nelayan di Pulau Ambon menggunakan alat tangkap cukup beragam. Namun kaitannya dengan tujuan penelitian ini yakni menentukan potensi dan tingkat pemanfaatan sumberdaya ikan demersal maka dipilih 4 jenis alat tangkap yang umumnya digunakan oleh nelayan, yaitu rawai, pancing tangan, bubu dan jaring insang tetap. Sedangkan data produksi yang digunakan adalah 5 jenis ikan yang dominan yakni ikan lencam (Lethrinus $s p$ ), kurisi (Etelis spp), kerapu (Epinephelus spp), Ikan merah (Lutjanus spp) dan ikan bubara (Caranx sp). Oleh karena kemampuan tangkap dari keempat jenis alat tangkap tersebut berbeda-beda maka perlu dilakukan standarisasi terhadap alat tangkap yang digunakan. Standarisasi dilakukan berdasarkan hasil analisis CPUE.

Umumnya penangkapan ikan lencam menggunakan 2 jenis alat tangkap yakni bubu dan pancing tangan. Hasil analisis CPUE diperoleh bahwa CPUE bubu 7.94 $\mathrm{kg} /$ trip lebih besar dari CPUE pancing tangan $1.03 \mathrm{~kg} /$ trip. Dengan demikian alat tangkap bubu dijadikan alat tangkap standar untuk menghitung potensinya. Ikan kurisi menggunakan 3 jenis alat tangkap yakni bubu, pancing tangan dan rawai. Hasil analisis diperoleh CPUE rawai 10.07 $\mathrm{kg} /$ trip lebih besar dari CPUE pancing tangan dan bubu masing-masing $0.58 \mathrm{~kg}$ dan $1.27 \mathrm{~kg} /$ trip. Hasil yang didapatkan memperbolehkan alat tangkap rawai digunakan untuk menghitung potensinya.

Ikan kerapu menggunakan 3 jenis alat yakni bubu, pancing tangan dan rawai. Hasil analisis menunjukkan CPUE rawai 43.67 $\mathrm{kg} /$ trip lebih besar dari CPUE bubu dan pancing tangan masing-masing $1.94 \mathrm{~kg}$ dan $10.26 \mathrm{~kg} /$ trip. Hasil analisis menunjukan bahwa alat tangkap rawai digunakan untuk menghitung potensinya. Kakap merah juga menggunakan 3 jenis alat yakni bubu, pancing tangan dan rawai. Hasil analisis CPUE menunjukkan bahwa rawai $13.5 \mathrm{~kg} /$ trip lebih besar dari CPUE pancing tangan dan bubu masing-masing $0.86 \mathrm{~kg} /$ trip dan $6.86 \mathrm{~kg} /$ trip. Sedangkan ikan Kuwe menggunakan 4 jenis alat tangkap yakni bubu, pancing tangan, rawe dan jaring insang dasar (bottom gill net). Hasil analisis menunjukkan bahwa CPUE rawai $12.27 \mathrm{~kg} /$ trip lebih besar dari CPUE tiga alat tangkap lainnya berturut-turut pancing tangan 1.87 $\mathrm{kg} /$ trip, gillnet $0.97 \mathrm{~kg} /$ trip dan terendah adalah alat tangkap bubu $0.17 \mathrm{~kg} /$ trip.

Penentuan potensimasing-masingjenis ikan menggunakan beberapa pendekatan bioekonomi yakni Disequilibrium Schaefer, Schaefer, Walter-Hilborn/WH, Schnute dan Yoshimoto dan Pooley/CYP. Namun, dalam analisis ini hanya sampai pada menentukan MSY (Maximum Sustainable Yield), tidak menghitung MEY (Maximum Economic Yield) dan OAY (Open Access Yield). Hasil perhitungan setiap pendekatan atau model terhadap masing-masing jenis ikan menunjukkan bahwa pendekatan atau model terbaik untuk jenis ikan Lencam (Lethrinus $s p$.) adalah Disequilibrium Schaefer. Model tersebut menghasilkan potensi pada tingkat lestari (MSY) 1575 ton 
pada upaya optimum 184.207 trip. Produksi rata-rata saat ini adalah 314.867 ton. Hasil analisis disajikan pada (Tabel 3).

Tingkat pemanfaatan rata-rata ikan lencam saat ini yaitu $19.19 \%$ atau dengan kata lain potensi yang belum dimanfaatkan kurang lebih $80 \%$. Jika didasarkan pada nilai MSY maka jumlah tangkapan yang diperbolehkan untuk jenis ikan tersebut adalah 1260 ton/tahun.

Model terbaik untuk jenis ikan kurisi juga sama yakni Disequilibrium Schaefer. Model tersebut menghasilkan MSY 67 ton pada upaya optimum 1.527 trip. Produksi rata-rata saat ini 39.984 ton. Hasil analisis disajikan pada (Tabel 4).

Tingkat pemanfaatan rata-rata ikan kurisi saat ini sebesar $59.63 \%$ atau dengan kata lain potensi yang belum dimanfaatkan sebesar 40.37\%. Jika didasarkan pada nilai MSY maka jumlah tangkapan yang diperbolehkan untuk jenis ikan ini adalah 53.60 ton/tahun.

Model terbaik untuk jenis ikan kerapu (Epinephelus spp) adalah Schaefer. Model tersebut menghasilkan MSY sebesar 572.02 ton pada upaya optimum 15.753 trip. Produksi rata-rata saat ini 178.92 ton. Hasil analisis disajikan pada (Tabel 5).

Tingkat pemanfaatan rata-rata ikan Kerapu saat ini sebesar $31.27 \%$ atau yang belum dimanfaatkan sebesar $68.72 \%$, jika didasarkan pada nilai MSY maka jumlah tangkapan yang diperbolehkan untuk jenis ikan tersebut adalah 457.6 ton/tahun.

Model terbaik untuk jenis ikan kakap merah (Lutjanus spp) adalah WalterHilborn/WH. Model tersebut menghasilkan MSY sebesar 146.83 ton pada upaya optimum 2.631 trip. Produksi rata-rata saat ini 67.704 ton. Hasil analisis disajikan pada (Tabel 6).

Tingkat pemanfaatan rata-rata ikan Kakap Merah saat ini sebesar $47.47 \%$ atau dengan kata lain potensi ikan kakap merah yang belum dimanfaatkan sebesar $52.52 \%$. Jika didasarkan pada nilai MSY maka jumlah tangkapan yang diperbolehkan untuk jenis ikan tersebut adalah 117.46 ton/tahun. Model terbaik untuk jenis ikan bubara (Caranx $s p$ ) adalah Walter-Hilborn/ WH. Model tersebut menghasilkan MSY sebesar 270.60 ton pada upaya optimum 3630 trip dengan produksi rata-rata 72.959 ton. Hasil analisis disajikan pada (Tabel 7).

Tingkat pemanfaatan rata-rata ikan bubara saat ini $26.96 \%$ atau yang potensi ikan kakap merah yang belum dimanfaatkan sebesar $73.03 \%$. Jika didasarkan pada nilai MSY maka jumlah tangkapan yang diperbolehkan untuk jenis ikan tersebut adalah 216.480 ton/tahun.

Hasil analisis potensi tersebut di atas memperlihatkan bahwa sumberdaya ikan demersal cukup potensial dan berpelung untuk dikembangkan guna meningkatkan ekonomi masyarakat, khususnya nelayan di Pulau Ambon, dan dapat dijadikan sebagai salah satu sumber pendapatan bagi pembangunan di daerah.

Tabel 1. Jenis dan ukuran ikan demersal di perairan Pulau Ambon

\begin{tabular}{cllccc}
\hline \multirow{2}{*}{ No } & \multicolumn{2}{c}{ Jenis Ikan } & \multicolumn{2}{c}{ Panjang (cm) TL } & \multirow{2}{*}{ Dominan } \\
\cline { 2 - 5 } & \multicolumn{1}{c}{ Nama Lokal } & \multicolumn{1}{c}{ Nama Ilmiah } & Minimum & Maksimum & \\
\hline 1 & Kerapu & Epinephelus spp. & 20 & 70 & $\sqrt{ }$ \\
2 & Kerapu macan & Epinephelus guttatus & 30 & 120 & \\
3 & Sikuda & Lethrinus lencam & 25 & 40 & $\sqrt{ }$ \\
4 & Gaca & Lethrinus sp. & 15 & 45 & \\
5 & Bae Gamuru & Aphareus rutilans & 32 & 114 & \\
6 & Bae perempuan & Etelis carbunculus & 40 & 80 & \\
7 & Bae laki-laki & Etelis radiosus & 30 & 110 & $\sqrt{ }$ \\
8 & Bae ekor bandera & Etelis coruscns & 30 & 114 & \\
9 & Silapa & Pristopomoides spp. & 15 & 60 & \\
10 & Kuwe & Caranx sp. & 30 & 70 & $\sqrt{ }$ \\
11 & Hiu/kaluyu & Carcharias sp. & 45 & 150 & \\
\hline
\end{tabular}


Tabel 1 (lanjutan)

\begin{tabular}{|c|c|c|c|c|c|}
\hline \multirow{2}{*}{ No } & \multicolumn{2}{|c|}{ Jenis Ikan } & \multicolumn{2}{|c|}{ Panjang (cm) TL } & \multirow{2}{*}{ Dominan } \\
\hline & Nama Lokal & Nama Ilmiah & Minimum & Maksimum & \\
\hline 12 & Taruri & Caranx sp. & 50 & 75 & \\
\hline 13 & Ikan merah & Lutjnus spp. & 35 & 90 & $\sqrt{ }$ \\
\hline 14 & Salmaneti & Parupeneus spp. & 20 & 45 & \\
\hline 15 & Kakatua & Catoscarus sp. & 15 & 40 & \\
\hline 16 & Parang-parang & Trichiurus savala & 70 & 150 & \\
\hline 17 & Piscada & Sphyraena sp. & 40 & 80 & \\
\hline 18 & Gorango & Lutjanus sp. & 20 & 40 & \\
\hline 19 & Gurara & Lutjanus sp. & 15 & 40 & \\
\hline 20 & Maming & Cheilinus sp. & 40 & 150 & \\
\hline 21 & Kakas-kapas lau & Gerres sp. & 20 & 40 & \\
\hline 22 & Bambangan & Nemipteridae $s p$. & 20 & 50 & \\
\hline
\end{tabular}

Tabel 2. Distribusi Ikan Demersal di Perairan Pulau Ambon berdasarkan wilayah penangkapan dan musim

\begin{tabular}{|c|c|c|}
\hline $\begin{array}{c}\text { Wilayah Penangkapan/ } \\
\text { Letak }\end{array}$ & Lokasi Tangkap & Musim/Puncak Tangkap \\
\hline I Leihitu & 1 Tanjung Liang & Timur (Mei-September) \\
\hline $\begin{array}{l}3.6010^{\prime}-3.70 .26^{\prime} \text { LS- } \\
\text { 128.10.30' - } 128.20 .30^{\prime \prime} \text { BT } \\
\text { dan 3.60.10'-3.60.45' LS } \\
127.90-127.110 \mathrm{BT}\end{array}$ & $\begin{array}{ll}2 & \text { Tanjung Setan } \\
3 & \text { Muka Labuhan Morela } \\
4 & \text { Laut Mamala } \\
5 & \text { Labuhan negeri Hitu Lama } \\
\text { s/d belakang benteng (Hila) } \\
6 \text { Labuhan Negeri Lima } \\
7 \text { Palau Tiga }\end{array}$ & \\
\hline II Teluk Ambon Luar & 8 Tg. Tapi & $\begin{array}{l}\text { Peralihan II-Barat } \\
\text { (September-Februari) }\end{array}$ \\
\hline $\begin{array}{l}3.7020^{\prime}-3.7040^{\prime} \text { LS - } \\
127048^{\prime}-12801^{\prime} \text { BT dan } \\
3.70 .10^{\prime}-3.80 \text { LS dan } \\
127.90-128.10 \mathrm{BT}\end{array}$ & $\begin{array}{l}9 \text { Pemancar } \\
10 \text { Labuhan Negeri Alang } \\
11 \text { Labuhan Negeri Hatu-Laha }\end{array}$ & \\
\hline III Nusaniwe & 12 Batu Gelang & $\begin{array}{l}\text { Peralihan II-Barat (September } \\
\text {-Februari) }\end{array}$ \\
\hline $\begin{array}{l}\text { 3.70.30' - 3.80.10'.09" LS- } \\
\text { 127051',9" - 1280.20'39" } \\
\text { BT dan 3.70.30'-3.80 LS- } \\
\text { 127048'- } 1280.45^{\prime} \text { BT }\end{array}$ & $\begin{array}{l}13 \text { Pantai Nama } \\
14 \text { Batu Pintu } \\
15 \text { Batu Naku } \\
16 \text { Batu Badiri } \\
17 \text { Tg Lau }\end{array}$ & \\
\hline IV Leitimur Selatan & 18 Wailirang & Barat (Desember - Februari) \\
\hline $\begin{array}{l}3.60 .10^{\prime}-3.70 .15^{\prime} \text { LS- } \\
128.20-128.30 .40^{\prime} \mathrm{BT} \\
\text { dan 3.7005'-3.70.40' LS- } \\
1280.2^{\prime}-1280.40^{\prime} \mathrm{BT}\end{array}$ & $\begin{array}{l}19 \text { Liang } \\
20 \text { Batu Ayam } \\
21 \text { Labuhan Hukurila } \\
22 \text { Tg Hao } \\
23 \text { Batu Tongka } \\
\text { 24 Saaru } \\
\text { 25 Laut Tial } \\
\text { 26 Teluk Baguala }\end{array}$ & \\
\hline
\end{tabular}


Tabel 2 (lanjutan)

\begin{tabular}{lll}
\hline \multicolumn{1}{c}{ Wilayah Penangkapan/Letak } & \multicolumn{1}{c}{ Lokasi Tangkap } & \multicolumn{1}{c}{ Musim/Puncak Tangkap } \\
\hline V Perairan Salahutu & 27 Tg Tial & Sepanjang Tahun \\
3.5010' -3.60.48' LS - & 28 Hurnala & \\
128.20.40'-128.30.40' BT & 29 Mamoking & \\
& 30 Pulau Pombo & \\
\hline
\end{tabular}

Tabel 3. Hasil analisis potensi ikan Lencam (Lethrinus sp.) dengan berbagai pendekatan bioekonomi

\begin{tabular}{|c|c|c|c|c|c|c|c|c|c|}
\hline \multirow[b]{2}{*}{ No } & \multirow{2}{*}{$\begin{array}{l}\text { Mode } \\
\text { Bioekonomi }\end{array}$} & \multicolumn{3}{|c|}{ Jenis Ikan } & \multirow[b]{2}{*}{$\mathrm{R}^{2}$} & \multirow{2}{*}{$\begin{array}{c}\text { Significance } \\
\text { F }\end{array}$} & \multirow{2}{*}{$\begin{array}{l}\text { MSY } \\
\text { (ton) }\end{array}$} & \multirow{2}{*}{$\begin{array}{c}\text { Effort } \\
\text { Optimum }\end{array}$} & \multirow{2}{*}{$\begin{array}{l}\text { Produksi } \\
\text { rata-rata } \\
\text { (ton) }\end{array}$} \\
\hline & & $\mathrm{a}$ & $\beta$ & $\gamma$ & & & & & \\
\hline 1 & $\begin{array}{l}\text { Dis equi- } \\
1 \text { i b r i m m } \\
\text { Schaefer }\end{array}$ & -0.9 & 116.9 & $\begin{array}{l}2.5824 E- \\
06\end{array}$ & 0.9 & 0.9 & 1575 & 184207 & 314.857 \\
\hline 2 & Schaefer & 0.00 & $6742 E-09$ & & 0.05 & 0.6 & 690 & 320442 & 314.857 \\
\hline 3 & $\begin{array}{l}\text { Walter- } \\
\text { Hilborn/ } \\
\text { WH }\end{array}$ & 0.4 & -97.0 & $1.122 E-06$ & 0.07 & 0.9 & 357.57 & 175833 & 314.857 \\
\hline 4 & Schnute & -0.7 & 87.4 & $3.356 E-06$ & 0.3 & 0.7 & 485.24 & 112580 & 314.857 \\
\hline 5 & $\begin{array}{l}\text { Clark, } \\
\text { Yoshi- } \\
\text { moto, and } \\
\text { Pooley/CYP }\end{array}$ & -1.7 & 0.747 & $2.428 E-06$ & 0.4 & 0.5 & 12.73 & 26001 & 314.857 \\
\hline
\end{tabular}

Tabel 4. Hasil analisis potensi ikan Kurisi (Etelis spp) dengan berbagai pendekatan bioekonomi

\begin{tabular}{|c|c|c|c|c|c|c|c|c|c|}
\hline \multirow[b]{2}{*}{ No } & \multirow{2}{*}{$\begin{array}{l}\text { Mode } \\
\text { Bioekonomi }\end{array}$} & \multicolumn{3}{|c|}{ Jenis Ikan } & \multirow[b]{2}{*}{$\mathrm{R}^{2}$} & \multirow{2}{*}{$\begin{array}{c}\text { Significance } \\
\text { F }\end{array}$} & \multirow{2}{*}{$\begin{array}{l}\text { MSY } \\
\text { (ton) }\end{array}$} & \multirow{2}{*}{$\begin{array}{c}\text { Effort } \\
\text { Optimum }\end{array}$} & \multirow{2}{*}{$\begin{array}{l}\text { Produksi } \\
\text { rata-rata } \\
\quad \text { (ton) }\end{array}$} \\
\hline & & $a$ & $\beta$ & $\gamma$ & & & & & \\
\hline 1 & $\begin{array}{l}\text { Dis equi- } \\
1 \mathrm{ibrium} \\
\text { Schaefer }\end{array}$ & -1.8 & 22.69 & 0.00 & 0.8 & 0.9 & 67 & 1527 & 39.95 \\
\hline 2 & Schaefer & 0.04 & -4.65 & & 0.32 & 0.6 & 94.90 & 4516 & 39.95 \\
\hline 3 & $\begin{array}{l}\text { Walter- } \\
\text { Hilborn/ } \\
\text { WH }\end{array}$ & -0.13 & -3.92 & 0.00 & 0.16 & 0.9 & 4.86 & 283 & 39.95 \\
\hline 4 & Schnute & -0.7 & 14.9 & 3.74 & 0.15 & 0.7 & 2485.7 & 99.734 & 39.95 \\
\hline 5 & $\begin{array}{l}\text { Clark, } \\
\text { Yoshi- } \\
\text { moto, and } \\
\text { Pooley/CYP }\end{array}$ & -2.8 & 0.01 & -0.00 & 0.50 & 0.5 & 33.79 & 1.267 & 39.95 \\
\hline
\end{tabular}


Tabel 5. Hasil analisis potensi ikan Kerapu (Epinephelus spp) dengan berbagai pendekatan bioekonomi

\begin{tabular}{|c|c|c|c|c|c|c|c|c|c|}
\hline \multirow[b]{2}{*}{ No } & \multirow{2}{*}{$\begin{array}{l}\text { Mode } \\
\text { Bioekonomi }\end{array}$} & \multicolumn{3}{|c|}{ Jenis Ikan } & \multirow[b]{2}{*}{$\mathrm{R}^{2}$} & \multirow{2}{*}{$\begin{array}{c}\text { Significance } \\
\text { F }\end{array}$} & \multirow{2}{*}{$\begin{array}{l}\text { MSY } \\
\text { (ton) }\end{array}$} & \multirow{2}{*}{$\begin{array}{c}\text { Effort } \\
\text { Optimum }\end{array}$} & \multirow{2}{*}{$\begin{array}{l}\text { Produksi } \\
\text { rata-rata } \\
\text { (ton) }\end{array}$} \\
\hline & & a & $\beta$ & $\gamma$ & & & & & \\
\hline 1 & $\begin{array}{l}\text { Dis equi- } \\
1 \mathrm{ibrium} \\
\text { Schaefer }\end{array}$ & 23.3 & -205.5 & -0.00 & 0.96 & 0.2 & 38 & 7.843 & 178.919 \\
\hline 2 & Schaefer & 0,07 & $-2.3 \mathrm{E}$ & & 0.61 & 0.06 & 572 & 15.753 & 178.919 \\
\hline 3 & $\begin{array}{l}\text { Walter- } \\
\text { Hilborn/ } \\
\text { WH }\end{array}$ & 1.07 & 13.8 & $-3.4 \mathrm{E}$ & 0.3 & 0.7 & 610 & 15.765 & 178.919 \\
\hline 4 & Schnute & 1.74 & -23 & $-9.8 \mathrm{E}$ & 0.12 & 0.87 & 336.98 & 8.870 & 178.919 \\
\hline 5 & $\begin{array}{l}\text { Clark, } \\
\text { Yoshi- } \\
\text { moto, and } \\
\text { Pooley/CYP }\end{array}$ & -4.1 & -0.86 & -0.00 & 0.88 & 0.11 & 210 & 3.830 & 178.919 \\
\hline
\end{tabular}

Tabel 6. Hasil analisis potensi ikan Kakap Merah (Lutjanus spp) dengan berbagai pendekatan bioekonomi

\begin{tabular}{|c|c|c|c|c|c|c|c|c|c|}
\hline \multirow{2}{*}{ No } & \multirow{2}{*}{$\begin{array}{l}\text { Mode } \\
\text { Bioekonomi }\end{array}$} & \multicolumn{3}{|c|}{ Jenis Ikan } & \multirow{2}{*}{$\mathrm{R}^{2}$} & \multirow{2}{*}{$\begin{array}{c}\text { Significance } \\
\text { F }\end{array}$} & \multirow{2}{*}{$\begin{array}{l}\text { MSY } \\
\text { (ton) }\end{array}$} & \multirow{2}{*}{$\begin{array}{c}\text { Effort } \\
\text { Optimum }\end{array}$} & \multirow{2}{*}{$\begin{array}{l}\text { Produksi } \\
\text { rata-rata } \\
\quad \text { (ton) }\end{array}$} \\
\hline & & $a$ & $\beta$ & $\gamma$ & & & & & \\
\hline 1 & $\begin{array}{l}\text { D is equi- } \\
1 \text { i b r i m } \\
\text { Schaefer }\end{array}$ & -1.5 & 43.47 & 0.00 & 0.99 & 0.01 & 97 & 4.215 & 69.704 \\
\hline 2 & Schaefer & 0,01 & $-3,42$ & & 0.34 & 0.21 & 206.9 & 24.565 & 69.704 \\
\hline 3 & $\begin{array}{l}\text { Walter- } \\
\text { Hilborn/ } \\
\text { WH }\end{array}$ & -0.90 & 8.11 & 0.00 & 0.72 & 0.27 & 146.83 & 2631 & 69.704 \\
\hline 4 & Schnute & -1.12 & 51.91 & 1.43 & 0.25 & 0.74 & 426.32 & 39.258 & 69.704 \\
\hline 5 & $\begin{array}{l}\text { Clark, } \\
\text { Yoshi- } \\
\text { moto, and } \\
\text { Pooley/CYP }\end{array}$ & -2.01 & 0.52 & -1.91 & 0.48 & 0.51 & 42.95 & 6.144 & 69.704 \\
\hline
\end{tabular}

Tabel 7. Hasil analisis potensi ikan Kuwe (Caranx sp.) dengan berbagai pendekatan bioekonomi

\begin{tabular}{|c|c|c|c|c|c|c|c|c|c|}
\hline \multirow[b]{2}{*}{ No } & \multirow{2}{*}{$\begin{array}{l}\text { Mode } \\
\text { Bioekonomi }\end{array}$} & \multicolumn{3}{|c|}{ Jenis Ikan } & \multirow[b]{2}{*}{$\mathrm{R}^{2}$} & \multirow{2}{*}{$\begin{array}{c}\text { Significance } \\
\mathrm{F}\end{array}$} & \multirow{2}{*}{$\begin{array}{l}\text { MSY } \\
\text { (ton) }\end{array}$} & \multirow{2}{*}{$\begin{array}{c}\text { Effort } \\
\text { Optimum }\end{array}$} & \multirow{2}{*}{$\begin{array}{l}\text { Produksi } \\
\text { rata-rata } \\
\quad \text { (ton) }\end{array}$} \\
\hline & & a & $\beta$ & $\gamma$ & & & & & \\
\hline 1 & $\begin{array}{l}\text { D is equi- } \\
1 \mathrm{i} \mathrm{b} \mathrm{r} \mathrm{i} \mathrm{m} \\
\text { Schaefer }\end{array}$ & 4.48 & -32.45 & -0.001 & 0.67 & 0.57 & 61 & 2.006 & 72.959 \\
\hline 2 & Schaefer & 0.10 & -1.02 & & 0.28 & 0.27 & 247.02 & 4.903 & 72.959 \\
\hline 3 & $\begin{array}{l}\text { Walter- } \\
\text { Hilborn/ } \\
\text { WH }\end{array}$ & 10.22 & -68.56 & -0.00 & 0.51 & 0.48 & 270.60 & 3630 & 72.959 \\
\hline 4 & Schnute & 0.66 & 6.56 & -0.00 & 0.32 & 0.67 & 25.75 & 506 & 72.959 \\
\hline 5 & $\begin{array}{l}\text { Clark, } \\
\text { Yoshi- } \\
\text { moto, and } \\
\text { Pooley/CYP }\end{array}$ & -6.29 & -0.78 & 0.00 & 0.50 & 0.49 & 62.45 & 64232 & 72.959 \\
\hline
\end{tabular}




\section{KESIMPULAN}

Kesimpulan penelitian ini adalah potensi ikan demersal yang ditemukan di perairan Pulau Ambon selama penelitian sebanyak 22 jenis, 5 jenis diantaranya dipakai dalam analisis, dan potensi lestari (MSY) jenis ikan lencam 1575 ton dengan tingkat pemanfaatan saat ini sebesar $19.19 \%$, ikan kurisi 67 ton dengan tingkat pemanfaatan saat ini sebesar 59.63\%, ikan kerapu 572.02 ton dengan tingkat pemanfaatan saat ini sebesar $31.27 \%$, kakap merah 146.83 ton dengan tingkat pemanfaatan saat ini sebesar $47.47 \%$, ikan bubara 270.60 ton dengan tingkat pemanfaatan saat ini sebesar $26.96 \%$.

\section{DAFTAR PUSTAKA}

Allen GR, Steener PH, Deloach N. 2003. Reef Fish Identification Tropical Pacific. Florida: Jacksonvile.

Anderson WD Jr, Allen GR. 2001. Species Identification Guide for Fishery Purposes. The living marine resources of the Western Central Pacific. Rome, FAO

Badrudin, Karyana. 1992. Indek Kelimpahan Stok Sumberdaya Ikan Demersal di Perairan Barat Kalimantan. Jakarta: BPPL

Dahdouh-Guebas F, Jayatissa LP, Di Nitto D, Bosire JO, Lo Seen D, Koedam N. 2005. How effective weremangroves as a defenceagaints the recent tsunami Curr. Bio. 15: R443-R447.

FAO. 1995. Code of conduct for responsible fisheries. http://www.fao.org/fi/ agreem/agreem.asp.

FAO. 2009. Safety guide for small fishing boats. Rome, Italy. FAO

Fauzi A, Anna S. 2005. Pemodelan Sumber Daya Perikanan dan Kelautan untuk Analisis Kebijakan. Jakarta: PT. Gramedia Pustaka Utama.

Kar TK, Chakraborty K. 2009. Bioeconomic analysis of Maryland's Chesapeake
Bay oyster fishery with reference to the optimal utilization and management of the resource. International Journal of Engineering, Science and Technology. (1):172-189.

Lopez-Hoffman L, De-Noyer JL, Munroe I, Shaftel R, Anten RPL, Mart Anten, Matrines-Ramos M, Ackerly DD. 2006. Mangrove seedling net photosinthesis, growth and survivorship are interactively affected by salinity and light. Biotropica Pr.

Moffitt RB. 2003. Biological data and stock assessment methodologies for deepslope bottom fish resources in the Hawaiian archipelago. Workshop papers. Deep Sea 2003. Conference of Governance and Management of Deep-sea Fisheries. FAO Fisheries Proceedings 3/2.

Naamin N, Harjamulia A. 1990. Potensi, pemanfaatan dan penggelolaan sumber daya perikanan. Jakarta: Prosiding forum perikanan, Balai Peneliti Perikanan Laut

Odum HT, Odum EP. 1955. Trophic structure and productivity of a windward coral reef community on Eniwetok Atoll. Ecol. Monogr. (25):291-320.

Rahmat E. 2007. Penggunaan pancing ulur untuk menangkap ikan pelagis besar. LIPI Jurnal.

Raiston, Povina 1985. Tropical snappers and grouper. Biologi and fisheries management with the complement of FAO/UNDP. Seafarming Development Project INS/ 81008.

Smith IR. 1983. A resource framework for traditisonal fisheries. Jurnal ICLARM. Manila.

Wagiu M. 2009. Investasi terbatas bagi nelayan pancing ulur di Malalayang I Manado. Pacific Jurnal. 1(4) :546-550.

Zid M. 2011. Fenomena strategi nafkah keluarga nelayan: adaptasi ekologis di Cikahuripan-Cisolok, Sukabumi. Jurnal Sosialita. (9):32-38 